\title{
THE LEARNING DESIGN FOR MEDIATION TRAINING THROUGH ONLINE ENVIRONMENTS: GETTING TO THE FIFTH LANGUAGE SKILL
}

\author{
$\mathrm{M}^{\mathrm{a}}$ Mercedes Rico Garcia ${ }^{1}$, Laura V. Fielden Burns ${ }^{2}$ and María José Naranjo Sánchez ${ }^{1}$ \\ University of Extremadura \\ ${ }^{1}$ Centro Universitario de Mérida, Santa Teresa de Jornet, 38, 06800 Mérida, Spain \\ ${ }^{2}$ Faculty of Teacher Traning, Campus Universitario, S/N, Cáceres, Spain
}

\begin{abstract}
From the skills needed to adjust for the current mismatch between labor market demands and higher education training, collaboration and the development of communication strategies stand out. To improve communication as a whole, The Common European Framework of Reference for Languages (CEFR), constitutes a body of reference which adds to the traditional skills new descriptors such as mediation and online interaction. The study constitutes a step towards the identification and design of online training to develop foreign languages mediation competences through virtual environments; that is, the reconstruction of meaning through online production, reception, culture and interaction practices. The contextualization for doing so is a unique one that is relevant to intercultural competences: critical incidents, which will form the basis of the contextualization of learning activities for the proposal. The learning proposal, resulting in the active involvement of students after previous phases of practical experimentation in virtual environments, and the set of parameters guiding the design constitute the main implications of the study.
\end{abstract}

\section{KEYWORDS}

Mediation, CEFR, Online Teaching, Critical Incident

\section{INTRODUCTION}

The identification of skill gaps between labor market expectations and academic training has forced higher education institutions to reflect on whether universities provide the necessary training to satisfy academic and market demands. The 2018 report 'The Global Graduate Skills Gap in the 21st Century' examining the relationship between graduate skills and employer needs has exposed the skills gap to be a global and worldwide issue. This mismatch in expectations between students and employers needs to be urgently addressed to bridge both sides, making students understand how employers value skills and universities train students in specific areas for successful employment. Among other actions, it has resulted in the adoption of competence-based approaches where students acquire not only specific competences, but master other skills, transferable to a great deal of occupational situations (Rico et al., 2013; Pérez et al., 2010).

In this context, we can raise a question concerning the identification of the skills needed for better employability in the coming years. With the world advancing so fast, it seems to be obvious that the skills needed are also rapidly changing. However, while the digital world and its consequences on the labor market are expanding, soft skills like communication, problem-solving, collaboration, team work, creativity, etc. are becoming as valued as technological knowledge and expertise. In this sense, the World Economic Forum reports that the ten skills needed to thrive in 2020 are: 
Table 1. Skills for 2020 according to the World Economic Forum

\begin{tabular}{|l|l|}
\hline 2020 skills \\
\hline$\bullet$ Complex problem solving. & $\bullet$ Emotional intelligence. \\
\hline$\bullet$ Critical thinking. & $\bullet$ Judgement and decision making. \\
\hline$\bullet$ Creativity. & $\bullet$ Service orientation. \\
\hline$\bullet$ People management. & $\bullet$ Negotiation. \\
\hline$\bullet$ Coordinating with others. & $\bullet$ Cognitive flexibility \\
\hline
\end{tabular}

In most of these skills, collaboration and communication strategies need to be further trained, which brings us to the need to develop overall communication techniques and other language related skills, both in terms of their development in native languages (L1) and foreign languages (L2). Yet, how can we define these cross curricular abilities so as to improve communicative competences? A description validated internationally in terms of communication from a foreign language learning perspective is The Common European Framework of Reference for Languages (CEFR), a general framework which also includes scales of updated and new descriptors such as mediation and online interaction. Among these, mediation stands out as one of the leading interpersonal skills ("soft skills") of 21st century communication (North and Piccardo, 2016).

Although this framework was created with foreign language learning in mind, it was intended to generally cover the skills needed to communicate successfully, and to be widely applicable to any language, which makes it an appropriate reference for discussing language skills globally, as well. Although mediation has been included in the Common European Framework of Reference for Languages (Council of Europe 2001; 2018) and has been considered an ability users of a given language should possess so that they can participate in today's multicultural contexts, it has not received much attention and has rarely been included in foreign language curricula until recently. This dearth of research supports the need for further investigation.

In this context, the present study constitutes a step towards the identification of descriptors and the design of online training actions to develop foreign languages mediation competences through virtual environments. The research starts by presenting the theoretical framework which supports the study (mediation and online teaching environments). The learning proposal, constituting the main body of the study, consists of a theoretical set of parameters to follow in the design of mediation activities delivered through virtual environments and a set of practical instances to exemplify our teaching proposal.

\section{BODY OF PAPER}

\subsection{Theoretical Background}

\subsubsection{Mediation}

Coste \& Cavalli (2015: 12) noted that in terms of the objective of mediation skills, "The aim (...) is to reduce the gap between two poles that are distant from or in tension with each other", where mediation is based on the dynamic of the construction of meaning through production, reception, culture and interaction. These relationships are shown in Table 2:

Table 2. Mediation concepts

\begin{tabular}{|l|l|l|}
\hline \multirow{2}{*}{ Mediating communication } & \multicolumn{2}{|c|}{ Cognitive mediation } \\
\cline { 2 - 3 } & Mediating concepts & Mediating Texts \\
\hline Strengthening the effectiveness of & Collaborating with & Transmitting / \\
communication: & others to make a & summarizing / \\
- Creating a positive environment & decision or to solve a & synthesizing \\
- Showing cultural awareness & problem & information and \\
- Facilitating collaborative interaction & & ideas \\
- Resolving difficult situations & & Adaptation \\
\hline
\end{tabular}


Mediation practice is considered to be a key ingredient to intercultural communication, which, among others, focuses on social attributes, thoughts and cultural patterns, factors which are all linked to intercultural understanding, meaning decodification etc. Thus, mediation is defined as a process where users (meditators) are not concerned about expressing their own meanings, but are acting as an intermediary to extract messages from a verbal or visual, spoken or written text in one language, to achieve communicative goals. In this context, intercultural communication has also aroused great interest in the business world, (Moore, May \& Wold, 2012) since future professionals must face cultural differences in order to do their jobs successfully. Mediation training is consequently carried out in a variety of contexts and formats in academic and professional settings, emphasizing the suitability of small groups, in-class interaction, and, particularly, the use of role-play and simulations (Walsh, 2015).

\subsubsection{Critical Incidents as Context for Mediation}

One of the areas where mediation is particularly key is in the managing of what are known as critical incidents in intercultural contact situations, where conflicts of an intercultural nature, such as a misunderstanding about something originating in one's cultural experience, occurs, and is the trigger for a conflict of some kind. These "often derive from mismatches of expectations and are exacerbated by communication and intercultural issues" (Vannini et al, 2017). Previous studies have pointed to these contexts as excellent teaching resources for fomenting greater cultural awareness and understanding in foreign language students (Stakhnevich, 2002; Westwood, \& Ishiyama, 1990). What is essentially taught as a resolution to these cultural interactions are the skills of successful mediation, where the host of communicative skills participants utilize to understand one another and create meaning together despite their differences lead to better negotiation and more satisfying outcomes for both parties. We will suggest here that mediation training may use this teaching resource, critical incidents, as a model for contextualizing mediation, following in particular the framework of Brunello (2010; 2015), as adapted by Vannini, et al, 2017), which is based on intercultural communication studies and views the cultural component of critical incidents as fluid and contextually dependent (Vannini et al., 2017, 17).

\subsubsection{Critical Incident Analysis (CIA) as a Context for Developing Mediation Skills}

The CIA framework by Brunello (2015) notes that cultural incidents, those mismatches of expectations, can have a powerful consequence on relationships and thus outcomes. He gives as an example the bewilderment Belgian project partners experienced to find that their Burundian counterparts were not using the much-requested computer labs funded by their Belgian partners. The first step to analyzing this conflict was to understand what each party was taking for granted: the Belgians assumed that when a hard drive fails it must be fixed, while their counterparts assumed that when a hard drive fails the computer must stop being used, resulting in an empty lab. The CIA framework is based on the situation in which communication occurs, which must take into account "context, culture, history and stakeholders' different interests", such as those exemplified above (Vannini, et al., 2017, 19-20). The CIA framework includes reflection questions which we have organized into the following communicative phases:

Phase 1: Locating and naming expectations

Phase 2: Determining personal responses of mismatched expectations

Phase 3: Assessing level of consequence to mismatches

Phase 4: Reviewing the communicative process

To work these skills in depth, training should be delivered in a variety of contexts and formats where small group teaching, interactive, workshop-style approaches and, particularly, the use of role-play and simulations are emphasized (Walsh, 2015). This type of training must also be considered for a virtual environment, since demand for online learning has been growing, particularly in the higher and professional education sectors, with online enrollments continuing to increase year after year, and showing an increasing focus on teaching job-specific skills online (Friedman, 2018). Online higher education enrollments now outpace ordinary enrollments in university and changing demographics and employer needs are driving a radical shift in how learning is being accessed and consumed (Fong, Schroeder, \& Halfond, 2017). However, how can we activate and develop the mediation skills of students in virtual environments across different language proficiency levels when working in a foreign language learning context? 


\subsubsection{Mediation Tasks through Online Environments}

Since geographical barriers are one of the main shortcomings which hinder communicative interaction in many educational settings, with the help of ICT online simulations can be designed to enable users to interact with speakers of other languages and cultures. In agreement with Siegel (2010) and Jauregi \& Canto (2012), virtual environments can encourage interaction and facilitate mediation training. Analyzing a set of learning theories, interaction in online environments is also studied by Sadler (2012). The author states the importance of design relevant inputs to achieve successful language acquisition through virtual worlds.

In this line, Iwasaki (2014) claims that cultural competences can be trained by applying the "five Cs" that occur in this virtual world: Communication, Culture, Connections, Comparisons and Communities. Simultaneously, the explosion of online teaching and research in terms of language acquisition, the development of communicative competences and the chances for professional training, has been progressively increasing the demand of blended and /or virtual proposals, mainly in the higher and professional education sectors (Friedman, 2018). In this sense, and in line with our research objectives, efforts should be placed on designing training activities based on solid pedagogic approaches, technologically mediated, to design effective online mediation teaching proposals.

\subsection{Learning Design. Proposals to Develop Mediation Skills for Virtual Environments}

With the learner at the forefront of the learning process, an effective learning design involves taking decisions around creating pedagogically valuable learning activities where students can take on the role of mediators through teaching practices (role play, simulations, etc.) in appropriate learning scenarios. To reach this end, we can identify a set of considerations which should be taken into account in the design of effective learning proposals.

\subsubsection{Pedagogic Considerations}

1) The design of learning and teaching activities must be based on appropriate theoretical foundations. Here we turn to experiential learning, which according to Kolb (1984) is seen as a process where learners (1) are exposed to specific experiences, (2) observe and reflect on those situations, (3) create abstract concepts, and (4) test learning in future learning or professional situations.

2) Importance of role-plays to promote mediations (Alexander \& Lebaron, 2009; Raines et al.2010). Role play and simulations should provide feedback by tutors and peers which lead students to self-evaluation and reflection.

3) Following learning approaches as experiential learning (experiential learning cycles), the design of tasks (role play, simulations, etc.) broken into stages to maximize its efficiency. In this model, the role-play describes the concrete mediating experience, where the observation and reflection phases may give rise to new concepts that should be evaluated though further practice (a new role play, discussion, etc.)

4) If online training reveals any current and future teaching trend, it is that research and practice should be focused on designing experiential learning activities delivered online, not only by promoting reflection but also by encouraging active skill practice. Unfortunately, much of the content of courses on online mediation seems to consist exclusively of pre-recorded webinars and reading materials without any practical element. Determining what content should be included and how training should be delivered is key (Gonçalves \& Rainey, 2018).

5) The usage of quasi-real scenarios such as those presented in immersive platforms, augmented or virtual worlds (Second Life, Fablusi,) is also a good choice to enhance online role-play and simulation activities for a higher education context and professional training (Wills et al., 2011).

6) According to Matz \& Ebner (2011), aspects such as transferability should be considered, that is, preparing students for sitting at a real negotiation table; improving human-computer interaction, efficient administration and control, as well as promoting observation and feedback

7) According to Parlamis \& Mitchell (2014) in order for online role-play activities to be effective, they must be designed for the online environment, rather than merely replicated from a face-to-face setting. Parlamis \& Mitchell explicitly chose replication of an identical face-to-face course online, claiming that this replication may be greatly responsible for making online role-plays less effective. 


\subsection{Online Practice Proposals}

\subsubsection{Critical Incident Contextualization}

The activities developed follow a critical incident framework according Brunnello (2015), and lean on the Kolb experiential learning model as a methodological guide, whose phases are indicated in the table in italics. What follows is a basic overview of the structuring of the learning proposal in terms of its phasing and progression. It should be noted that prior to these phases students would undergo an introductory lesson on the nature of critical incidents, intercultural competency and mediation that would prepare them to work with these concepts. A general organizing framework for the activities, based on Kolb (1984) is seen is Table 3.

Table 3. Kolb (1984). Experiential learning applied framework for activities

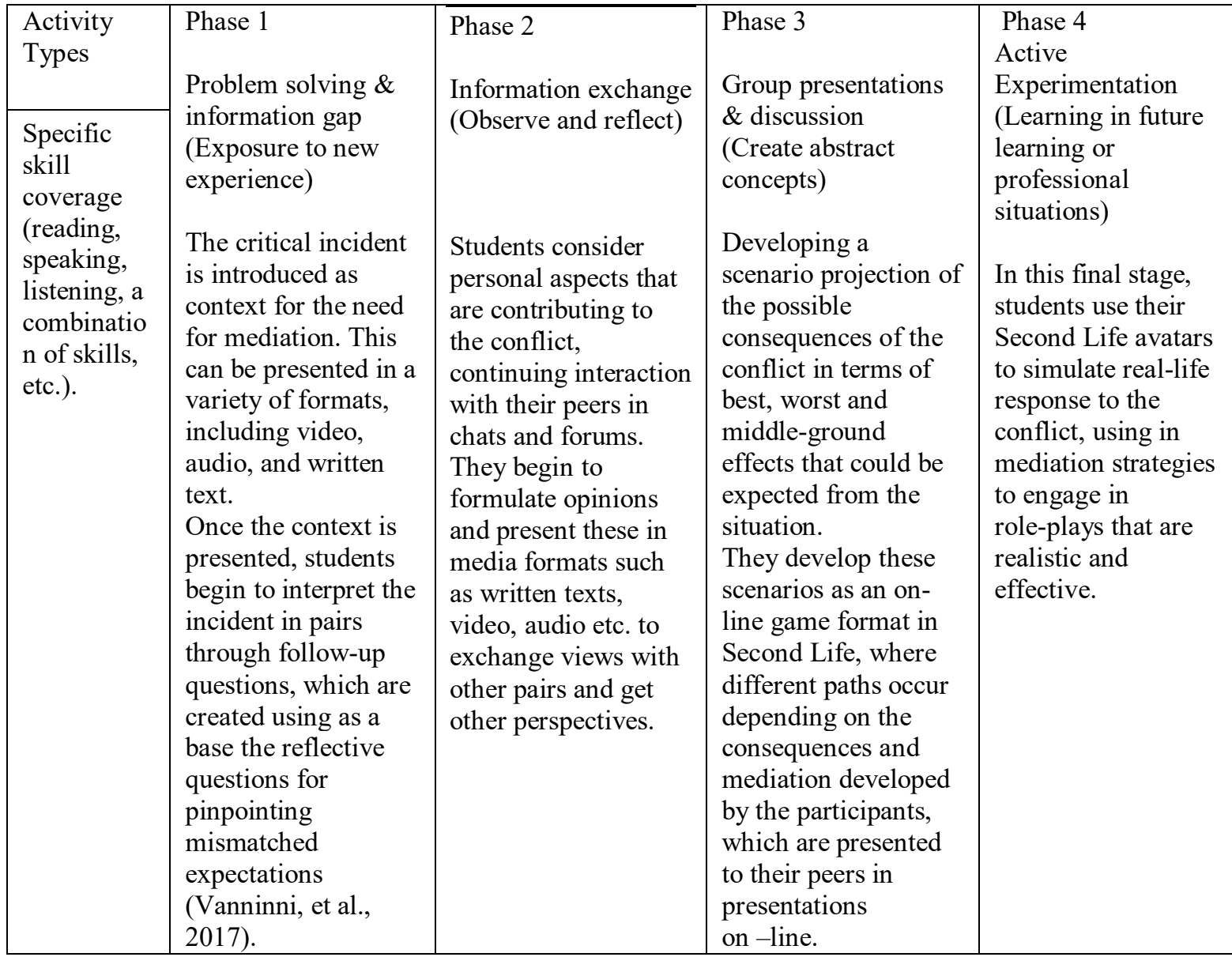

This framework would then be applied to a series of activities to be developed through a variety of ICT tools, including on-line forums and chats, wikis, blogs, virtual worlds such as Second Life, etc. For an example for how such activities can be designed Tables 4 and 5 show two examples of activity series that would allow students to progress through the phases of experiential learning and mediation strategies while working with critical incidents. 
Table 4. From critical incidents to active experimentation, example 1

\begin{tabular}{|c|c|}
\hline \multicolumn{2}{|c|}{ Mediation Activity 1} \\
\hline Phase in learning & Information gap: problem presentation \\
\hline Type & Processing oral speech \\
\hline Skill coverage & listening, writing \\
\hline ICT tool & On-line videos \\
\hline Mediation strategy & Identify and analyze mismatched expectations \\
\hline Description & $\begin{array}{l}\text { Students, in pairs, watch different videos of critical incidents and respond to follow- } \\
\text { up questions. They work in pairs to give short answers on what is going on and why, } \\
\text { using a guide. Critical incidents include situations where parties from different } \\
\text { cultures interact around the following scenarios: arriving late to class, looking at } \\
\text { written feedback from someone at work, using exam notes in class, smoking outside, } \\
\text { paying for group meals, etc. }\end{array}$ \\
\hline \multicolumn{2}{|c|}{ Mediation activity 2} \\
\hline Phase in learning & Mini-presentation and information exchange \\
\hline Type & Producing texts to construct meaning \\
\hline Skill coverage & writing \\
\hline Mediation strategy & Identify and analyze what personal responses occur \\
\hline ICT tool & Blogs \\
\hline Description & $\begin{array}{l}\text { In pairs, students produce a blog entry on a website called Cultural Perspectives: } \\
\text { Wherever You Go, There You Are to describe their particular critical incident to the } \\
\text { rest of the class. The objective is to define the critical incident in terms of the } \\
\text { mismatched expectations for a lay audience and make the cultural expectations clear. } \\
\text { They produce a blog as a class and do follow-up comments to one another's entries } \\
\text { with guided questions. }\end{array}$ \\
\hline \multicolumn{2}{|l|}{ Mediation activity 3} \\
\hline Phase in learning & Group presentations \\
\hline Type & Producing scenarios \\
\hline Skill coverage & writing, reading \\
\hline ICT tool & Digital presentations \\
\hline Mediation strategy & Understand consequences of mismatched expectations \\
\hline Description & $\begin{array}{l}\text { In pairs again students create a digital presentation on the possible consequences of } \\
\text { the critical incident and explain it in a video to show the variety of consequences the } \\
\text { critical incident might have in best case, worst case and a middle-ground scenario. }\end{array}$ \\
\hline \multicolumn{2}{|c|}{ Mediation activity 4} \\
\hline Phase in learning & Active experimentation \\
\hline Type & Role play \\
\hline Skill coverage & speaking, listening \\
\hline ICT tool & Second Life avatars \\
\hline Mediation strategy & Engage in metacommunication \\
\hline Description & $\begin{array}{l}\text { In pairs students do a role play of one of the scenarios with Second Life avatars they } \\
\text { have created before-hand, with mediation and communicative strategies in place. } \\
\text { These are recoded on-line, and their peers watch their role play and respond through } \\
\text { a designated forum with mediation strategy suggestions for improvement. Pairs then } \\
\text { return to the avatar role play to repeat with changes taking into account at least one } \\
\text { peer suggestion. These are recorded. }\end{array}$ \\
\hline
\end{tabular}




\section{CONCLUSION}

The CEFR pioneered the introduction of mediation as a skill traditionally ignored by other frameworks on reception and production competences. More than merely an additional skill, mediation includes a much- needed social dimension to language learning, the co-construction of meaning and its dynamic nature, including the relationship between the individual and social levels in language learning. Examining this co-construction in the context of critical incidents provides an ideal way for revealing how communication goes awry when factors of cultural relativity are considered. Critical incidents in this sense are an ideal via for mediation skills development since they focus on the reflective process needed for effective communication and the self-and others-awareness key to positive outcomes in difficult circumstances.

The descriptors and the learning design provided are the main implications of this study and may help test designers and item-writers to decide what mediation tasks to design for each level and what aspects of language to focus on. The experimental learning methodology followed in our research (Kolb, 1984), based on a cyclical process that results in active experimentation from previous phases of observation and reflection, can be applied to a great number of interactions in virtual worlds, in which learners can observe language and behavior and interiorize cultural competencies of other virtual word inhabitants. Virtual environments facilitate student-like-avatars' interaction among users and the world around them, affordances which include the facilitation of tasks that lead to enhanced spatial representation, and opportunities for experiential multicultural interaction within an environment where variables such as anxiety minimization, anonymity, and motivation are key for successful language learning. Some of the most important barriers preventing students from using a foreign language effectively are related to inhibitions and fear of negative criticism.

However, practical research must be done on what online learning design frameworks support effective virtual role-plays and how they can best guide the construction and implementation of those activities.

\section{REFERENCES}

Alexander, N., Lebaron, M. 2009. Death of the role-play. In C. Honeyman, J. Coben, \& G. De Palo (Eds.), Rethinking negotiation teaching: Innovations for context and culture. St. Paul, MN: DRI Press, pp. 179-197.

Brunello, P. 2010. ICT for education projects: a look from behind the scenes. Information Technology for Development, Vol. 16, No 3, pp. $232-239$.

Brunello, P. 2015. Broken Premises: Towards an Intercultural Understanding of Bilateral Co-operation in ICT for Education in Burundi (Doctoral dissertation). Royal Holloway University of London, London, UK. Retrieved fromhttps://pure.royalholloway.ac.uk/portal/en/publications/broken-premises-towards-an-intercultural-understanding obilateral-cooperation-in-icts-for-education-in-burundi(ed7d06ce-047b-403a342-5500223842ad).html

Common European Framework of Reference for Languages (CEFR): https://www.coe.int/en/web/common-europeanframework-reference-languages.

Council of Europe. 2001. Common European Framework of Reference for Languages: Learning, Teaching, Assessment (CEFR), CUP, Cambridge. Available on line at www.coe.int/lang-CEFR.

Coste, D and Cavalli, M. 2015. Education, mobility, otherness - The mediation function of schools, Council of Europe, Strasbourg, Chapter 3.1.1. www.coe.int/lang

Council of Europe (2018). Common European framework of reference for languages: learning, teaching, assessment - Companion volume with new descriptors. Strasbourg: Council of Europe Publishing. Available at www.coe.int/lang-cefr.

Friedman, J.2018. Expectations for online education in 2018. US News.

Fong, J., Schroeder, R., and Halfond, J. 2017. The changing landscape for professional and continuing education in the U.S. Washington, DC: University Professional and Continuing Education Association.

Gonçalves, A. M. and Rainey, D. 2018. Standards, qualifications, and certification for. International Journal of Online Dispute Resolution, Vol., Pp. 1-2.

Iwasaki, I. 2014. Exploring Second Life for effective English as a Foreign Language and Culture Learning (竹中暉雄教授退任記念号). 桃山学院大学人間科学, Vol.45, pp. 205-220.

Jauregi, K. and Canto, S. 2012. Enhancing meaningful oral interaction in Second Life. In Procedia - Social and Behavioral Sciences, Vol. 3, № 4, pp. $111-115$. 
Kolb, D. A.1984. Experiential learning: Experience as the source of learning and development (Vol. 1). Englewood Cliffs, NJ: Prentice-Hall.

Matz, D., and Ebner, N. 2011. Using role-play in online negotiation teaching. In C. Honeyman, J. Coben, \& G. De Palo (Eds.), Venturing beyond the classroom St Paul, MN: DRI Press, Vol. 2, pp. 293-317.

Moore, S., May, D., and Wold, K. 2012. Developing cultural competency in engineering through transnational distance learning. Transnational distance learning and building new markets for universities, pp. 210-228.

North, B. and Piccardo, E. 2016. Developing illustrative descriptors of aspects of mediation for the Common European Framework of Reference (CEFR). A Council of Europe project. Language Teaching Vol. 49, №3, pp. 1-5

Parlamis, J. D., and Mitchell, L. D. 2014. Teaching negotiations online. Negotiation Journal, Vol. 30, pp. 93-113.

Pérez, J.E. et al., 2010. Active learning and generic competences in an operating systems course. Engineering Journal of Education, Vol. 26, pp. 1484-1492.

Raines, S. S., Hedeen, T., and Barton, A. B. 2010. Best practices for mediation training and regulation: Preliminary findings. Family Court Review, Vol. 48, Na483; PP. 541-554.

Rico, M et al. J. 2013. Everything matters: Development of cross-curricular competences in engineering through Web 2.0 social objects, In: D.G. Sampson, P. Isaias, D. Ifenthaler, and J. M. Spector (Eds.), Ubiquitous and mobile learning in the digital age, Springer Science \& Business Media, New York, NY, pp. 139-157.

Sadler, R. 2012. Virtual Worlds for Language Learning: From Theory to Practice, New York, NY: Peter Lang.

Siegel, S. 2010. Gaining Cultural Intelligence through Second Life Learning Interventions. The International Conference on E-Learning in the Workplace.

Stakhnevich, J. 2002. Using critical incidents to teach cross-cultural sensitivity. The Internet TESL Journal, Vol. 8, Na 3.

Vannini, S., et al. 2017. Critical Incidents Analysis: mismatching expectations and reconciling visions in intercultural encounters. The Journal of Community Informatics, $\mathrm{Vol} 13, \mathrm{~N}^{\circ} 2$.

Walsh, S. 2015. Beyond the role-play-Re-thinking mediator education. Journal of Mediation \& Applied Conflict Analysis, Vol. 2, №2, pp.317-327.

Westwood, M. J. and Ishiyama, F. I. 1990. The communication process as a critical intervention for client change in cross-cultural counseling. The Journal of Multicultural Counseling and Development, Vol. 18, № 4, pp.1-6.

Wills, S., Leigh, E., and I, A. 2011. The power of role-based e-learning. New York, NY: Routledge. 